\title{
Bilateral abducens palsy in closed head injury: A comprehensive review of literature based on a case report
}

\author{
Sandeep BV ${ }^{1}$, Rekha KR르, Manpreet Singh Banga ${ }^{3}$, Anantha Kishan ${ }^{4}$, Vittal I Nayak, \\ Sneha Priya Prabhakar ${ }^{6}$ \\ ${ }^{1,3}$ Assistant Professor, ${ }^{4}$ Professor and Head, Department of Neurosurgery, Vydehi Institute of Medical Sciences and \\ Research Hospital, Bangalore, India, ${ }^{2}$ Assistant Professor, ${ }^{5}$ Professor and Head, Department of Ophthalmology, Vydehi \\ Institute of Medical Sciences and Research Hospital, Bangalore, India, ${ }^{6}$ Consultant Retina Surgeon, Devi Eye Hospital, \\ Bangalore, India
}

Isolated bilateral sixth nerve palsies are rare, particularly in the setting of trauma. Most post-head injury cases with bilateral abducens palsy involve either basal skull fractures, particularly clival fractures. We present a case of bilateral abducens palsy after closed head injury in a young male who presented to the emergency department and a comprehensive literature review based on our clinical case. A Medline search for bilateral abducens palsy in closed head injury showed 89 results. Articles were excluded if crush head injury, nontraumatic bilateral abducens nerve palsy, associated vascular malformations were reported. After thorough search and filtering of those articles, fifty-one publications were found which reported and discussed about traumatic bilateral abducens palsy with closed head injury. In these 51 articles, a total of 139 cases were recorded. Several theories have been postulated to explain mechanisms of abducens nerve injury in trauma both in immediate and delayed settings. In our case, patient presented with immediate onset of bilateral abducens palsy. On imaging, clival fracture was seen in CT brain, which can be attributed for the nerve injury. Cases with retroclival extradural haematoma had higher chances of multiple cranial nerve injuries. Cases with multiple basal skull fracture involving petrous temporal bone fracture had higher chances of facial nerve injury. Along with bilateral involvement, the poorer outcome for recovery can be related with the severity of the adduction deficit. Our case showed no improvement in bilateral abduction during follow-up at 6 months. Clinical presentation of traumatic bilateral abducens nerve palsy is rare following closed head trauma and is usually associated with other injuries which are incompatible with life. It can be associated with other nerve injuries depending on basal skull fractures.

Key words: Bilateral abducens palsy; Closed head injury; Clival fracture

\section{Access this article online}

\section{Website:}

http://nepjol.info/index.php/AJMS DOI: 10.3126/ajms.v12i10.38006 E-ISSN: 2091-0576

P-ISSN: $2467-9100$

Copyright (c) 2021 Asian Journal of Medical Sciences

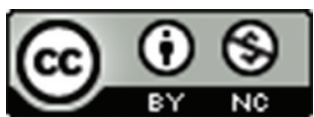

This work is licensed under a Creative Commons Attribution-NonCommercial 4.0 International License.

\section{INTRODUCTION}

Unilateral abducens nerve palsy has been reported to occur in $1 \%$ to $2.7 \%$ of all head trauma., ${ }^{1,2}$ The extended intracranial course of $6^{\text {th }}$ nerve along with its anatomical relationship to the petrous apex, makes it more susceptible to traumatic injury. ${ }^{3}$ Isolated bilateral sixth nerve palsies are rare, particularly in the setting of trauma. Most post-head injury cases with bilateral abducens palsy involve either basal skull fractures, particularly clival fractures or other intracranial pathologies with or without cervical spine injury. ${ }^{1}$

We present a case of bilateral abducens palsy after head injury in a young male who presented to the emergency department of our institute and a comprehensive literature review based on our clinical case. To the best of our knowledge, no publication in the literature discusses the total number of cases along with the imaging findings and clinical course of those cases. 


\section{MATERIALS AND METHODS}

A Medline search for key words "bilateral abducens palsy" and "closed head injury" showed 89 results. Publications were limited to those published in English. Articles were excluded if crush head injury, non-traumatic bilateral abducens nerve palsy, associated vascular malformations were reported. After thorough search and filtering of those articles, fifty-one publications were found which reported and discussed about traumatic bilateral abducens palsy with closed head injury. In these 51 articles, a total of 139 cases were recorded.

\section{RESULTS}

The results are summarized in Table 1 . The results include author, year of publication, associated cranial nerve injury, radiological findings, presentation and recovery wherever mentioned by the author in tabular form.

\section{CLINICAL CASE}

A 22-year-old male, pillion rider on a two -wheeler was involved in motor vehicle accident when they accidentally skid and fell. He sustained injury to the head. Patient had 2 episodes of vomiting and loss of consciousness post injury for 2 minutes with no history of seizures and nasal/ear bleed post injury. On arrival at the emergency department, he was haemodynamically stable. He was conscious, oriented and moving all four limbs. A secondary survey did not reveal any additional signs of injury or burns.

After the patient was stabilized, a detailed neurological examination revealed bilateral abducens nerve palsies along

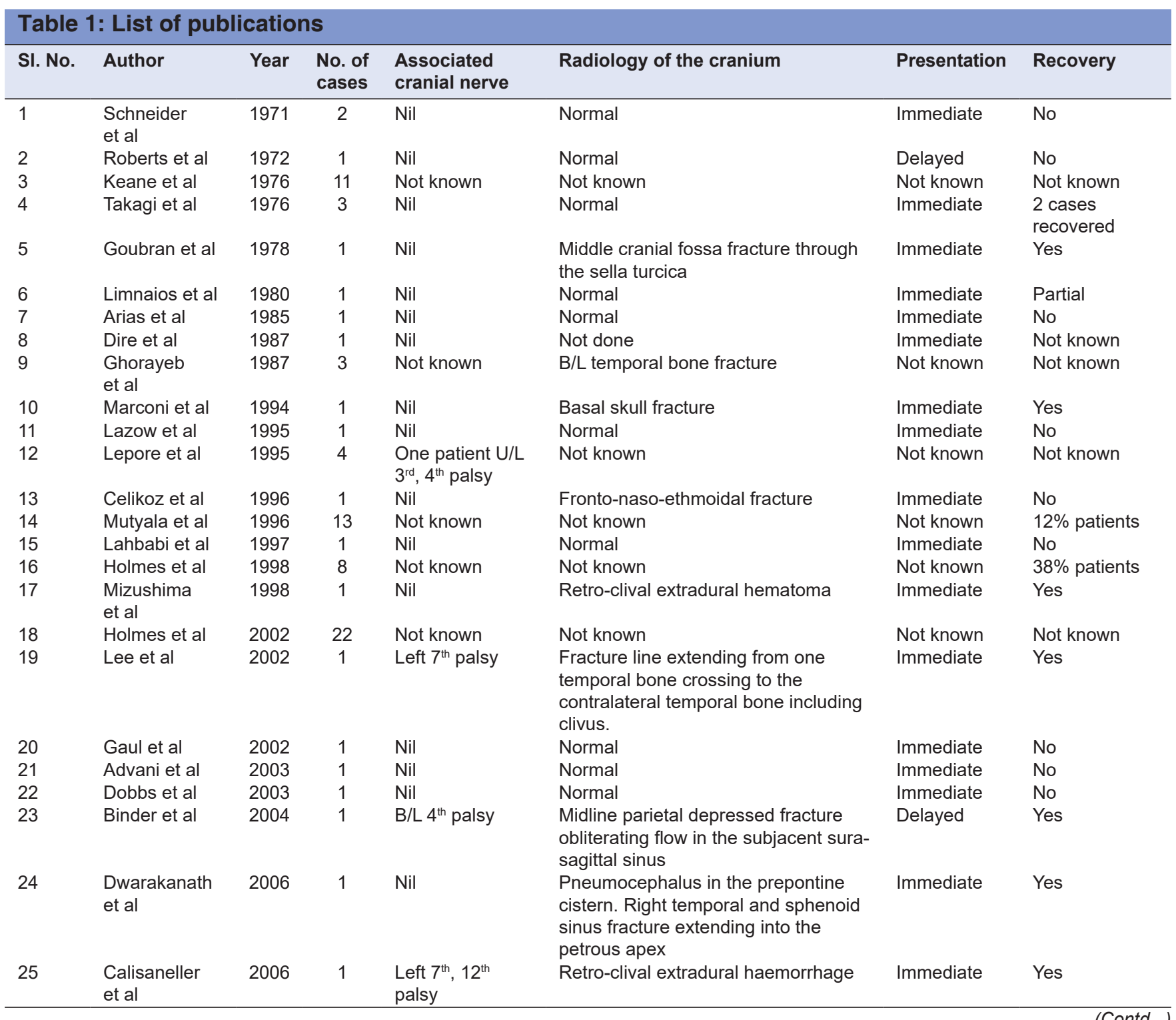




\begin{tabular}{|c|c|c|c|c|c|c|c|}
\hline SI. No. & Author & Year & $\begin{array}{l}\text { No. of } \\
\text { cases }\end{array}$ & $\begin{array}{l}\text { Associated } \\
\text { cranial nerve }\end{array}$ & Radiology of the cranium & Presentation & Recovery \\
\hline 26 & Durkin et al & 2006 & 29 & Not known & Not known & Not known & Not known \\
\hline 27 & $\begin{array}{l}\text { Ruiz-de-Río } \\
\text { et al }\end{array}$ & 2006 & 1 & Left $3^{\text {rd }}$ palsy & Diffuse axonal injury & Immediate & No \\
\hline 28 & Ratilal et al & 2006 & 1 & B/L $5^{\text {th }}$, left $12^{\text {th }}$ palsy & Retro-clival extradural haemorrhage & Immediate & No \\
\hline 29 & Katsuno et al & 2007 & 1 & Nil & $\begin{array}{l}\text { Bilateral petrous bones and clivus } \\
\text { fracture extending to the posterior } \\
\text { clinoid process }\end{array}$ & Immediate & No \\
\hline 30 & Schneck et al & 2007 & 1 & Nil & Pre-pontine extra-axial hematoma & Immediate & Yes \\
\hline 31 & Kwon et al & 2008 & 1 & Right $9^{\text {th }}, 12^{\text {th }}$ palsy & Retro-clival extradural haemorrhage & Immediate & Yes \\
\hline 32 & Taskin et al & 2009 & 1 & Nil & Normal & Immediate & Yes \\
\hline 33 & Nayil et al & 2010 & 1 & Nil & $\begin{array}{l}\text { Extradural hematoma in vertex with } \\
\text { parietal bone fracture }\end{array}$ & Delayed & Yes \\
\hline 34 & Pancko et al & 2010 & 1 & Left $7^{\text {th }}$ palsy & $\begin{array}{l}\text { Skull base fracture extending } \\
\text { transversely across the petrous bone } \\
\text { and right occipital bone, transverse } \\
\text { fracture across the sphenoid sinus } \\
\text { with extensive pneumocephalus }\end{array}$ & Immediate & No \\
\hline 35 & Tubbs et al & 2010 & 1 & Nil & Retro-clival extradural haemorrhage & Immediate & Yes \\
\hline 36 & $\begin{array}{l}\text { Palmowski- } \\
\text { Wolfe et al }\end{array}$ & 2010 & 1 & Nil & $\begin{array}{l}\text { Small bleedings in the brainstem and } \\
\text { in the left hemisphere }\end{array}$ & Delayed & No \\
\hline 37 & Czyz et al & 2011 & 1 & Nil & Normal & Immediate & No \\
\hline 38 & Yilmaz et al & 2011 & 1 & $\begin{array}{l}\text { Right } 7^{\text {th }}, 9^{\text {th }}, 12^{\text {th }} \\
\text { palsy }\end{array}$ & Retro-clival extradural haemorrhage & Immediate & Yes \\
\hline 39 & Lopes et al & 2011 & 1 & Nil & Avulsion of $6^{\text {th }}$ nerve & Immediate & No \\
\hline 40 & Salunke et al & 2012 & 2 & Nil & $\begin{array}{l}\text { Case } 1 \text {. Right convexity chronic } \\
\text { Subdural hematoma } \\
\text { Case } 2 \text {. Normal }\end{array}$ & $\begin{array}{l}\text { Delayed } \\
\text { Delayed }\end{array}$ & $\begin{array}{l}\text { Yes } \\
\text { No }\end{array}$ \\
\hline 41 & $\begin{array}{l}\text { Yanamadala } \\
\text { et al }\end{array}$ & 2012 & 1 & Nil & Normal & Immediate & Yes \\
\hline 42 & Nicot et al & 2012 & 1 & Nil & $\begin{array}{l}\text { Occipital, sellar and clival } \\
\text { fractures with pneumatocephalus } \\
\text { in interpeduncular cistern, } \\
\text { intraventricular hemorrhage }\end{array}$ & Immediate & No \\
\hline 43 & Selçuk et al & 2013 & 1 & U/L $12^{\text {th }}$ palsy & Normal & Immediate & Yes \\
\hline 44 & Fam et al & 2015 & 1 & Nil & $\begin{array}{l}\text { Left temporal fracture with frontal and } \\
\text { right corona radiata haemorrhagic } \\
\text { contusion }\end{array}$ & Immediate & No \\
\hline 45 & Orajiaka et al & 2015 & 1 & Nil & Bilateral temporal bone fractures & Immediate & No \\
\hline 46 & Salunke et al & 2016 & 1 & $\mathrm{~B} / \mathrm{L} 7^{\text {th }}$ palsy & $\begin{array}{l}\text { Oblique fracture of the left petrous } \\
\text { and right longitudinal petrous fracture } \\
\text { extending into the temporal squama } \\
\text { with pneumocephalus }\end{array}$ & Immediate & Yes \\
\hline 47 & Paiva et al & 2016 & 1 & Right $7^{\text {th }}$ palsy & $\begin{array}{l}\text { Retroclival and parenchyma } \\
\text { pneumocephalus, right temporal bone } \\
\text { fracture }\end{array}$ & Immediate & No \\
\hline 48 & Nguyen et al & 2016 & 1 & Nil & $\begin{array}{l}\text { Retroclival hematoma in both the } \\
\text { subdural and epidural space }\end{array}$ & Immediate & Yes \\
\hline 49 & Ravindran & 2017 & 2 & Nil & Case1. Normal & Delayed & No \\
\hline & et al & & & & Case 2. Avulsion of $6^{\text {th }}$ nerve & Immediate & No \\
\hline 50 & Serio et al & 2019 & 1 & Nil & Normal & Immediate & No \\
\hline 51 & Sahlu et al & 2020 & 1 & Nil & $\begin{array}{l}\text { Subacute retroclival subdural } \\
\text { hemorrhage with left cerebellar and } \\
\text { upper cervical spine extension }\end{array}$ & Immediate & No \\
\hline
\end{tabular}

with Grade 4 right facial nerve palsy according to HouseBrackman grading. Rest of the neurological examination was normal. His ophthalmological examination revealed his uncorrected vision on bedside in the both eyes was finger counting at $>3$ meters, colour vision was normal in both eyes. Both anterior and posterior segment were normal with no evidence of disc oedema. Abduction testing revealed inability to abduct past the midline bilaterally compatible with -4 abduction deficits. He complained of diplopia on both left and right horizontal gaze.

The CT (Computed tomography) Brain showed an extensive pneumocepahalus with pneumoventricles with a linear undisplaced fracture noted in squamous part of left temporal bone extending into the petrous part of ipsilateral temporal bone along with linear undisplaced 
fractures involving the body of sphenoid bone and linear undisplaced fracture noted in mastoid part of right temporal bone. Linear undisplaced fracture was also noted in the clivus [Figure 1]. Cervical spine CT screening was normal.

Patient was admitted in the ICU and treated with oxygen inhalation, head end elevation, antiepileptic and steroids. The serial CT scans of brain showed reduction in pneumocephalus and pneumoventricle. The MRI brain showed ventriculomegaly with pneumoventricle with no evidence of abducens nerve avulsion [Figure 2]. Patient was discharged and is on follow up. Eye signs have not improved on follow-up at 6 months, but facial palsy has improved to grade 2 according to House-Brackman grading.

\section{DISCUSSION}

\section{Anatomy of abducens nerve}

Abducens nerve vulnerability in traumatic brain injury is due to its tortuous and lengthy intracranial course. Anatomically it is divided into 5 segments: brain stem, subarachnoid space, petrous apex, cavernous sinus and orbit. ${ }^{4}$ Arising from the abducens nucleus in the floor of the fourth ventricle deep to the facial colliculus, nerve exits the brainstem at the pontomedullary junction, traversing anteriorly before ascending in the subarachnoid space posterior to the clivus. After approximately $1.5 \mathrm{~cm}$, nerve ascends over the ridge of the petrous bone and later passes under the petroclinoid (Gruber's) ligament. ${ }^{5}$ This triangular space demarcated by Gruber's ligament, the posterior clinoid process and the petrous apex is known as Dorello's canal. ${ }^{6}$ After passing through the canal, the nerve enters the cavernous sinus and then passes through superior orbital fissure to supply the lateral rectus muscle. Occasionally, the nerve bifurcates as it traverses Dorello's canal with one trunk passing superior to Gruber's ligament and the other passing inferior to it ${ }^{7}$ [Figure 3$]^{8}$. Bilateral abducens palsy following head injury is a rare but a welldescribed entity particularly when associated with skull base fractures. Several theories have been postulated to explain mechanisms of abducens nerve injury in trauma.

In 1971, Schneider et al., postulated that upward movement of the brain could result in compression of the abducens nerve against the rigid Gruber's ligament leading to avulsion of nerve. ${ }^{9}$ However, a 1976 case series which included 3 cases by Takagi et al., disputed this hypothesis, arguing that the injury of the abducens nerve below Gruber's ligament by the dura and the petrous apex prevented the injury to the abducens nerve by upward cranial displacement. Rather, they hypothesized that the force

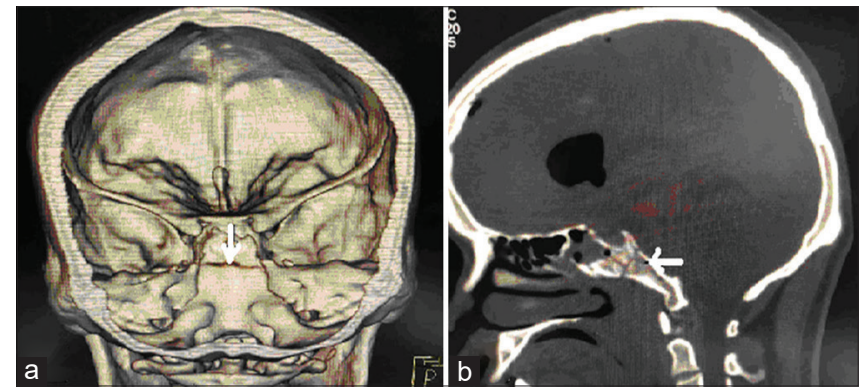

Figure 1: (a \& b). Computed Tomography of skull showing linear undisplaced clival fracture

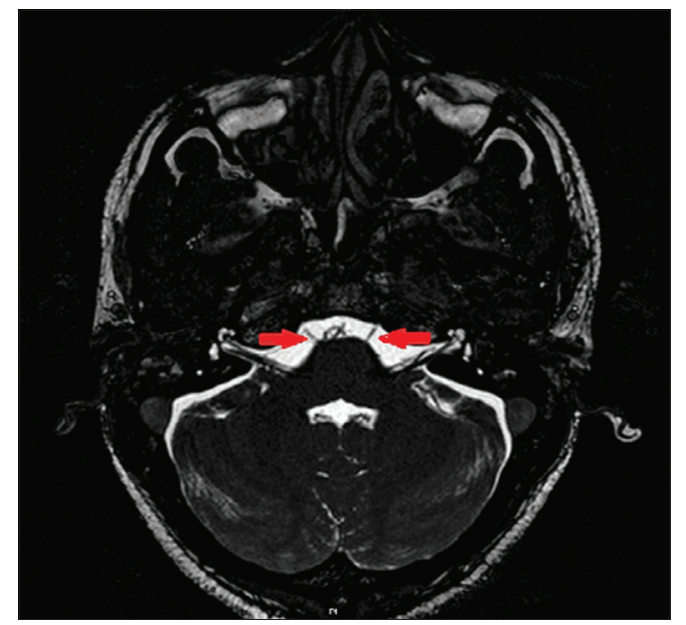

Figure 2: Magnetic resonance imaging showing $B / L$ abducens nerve

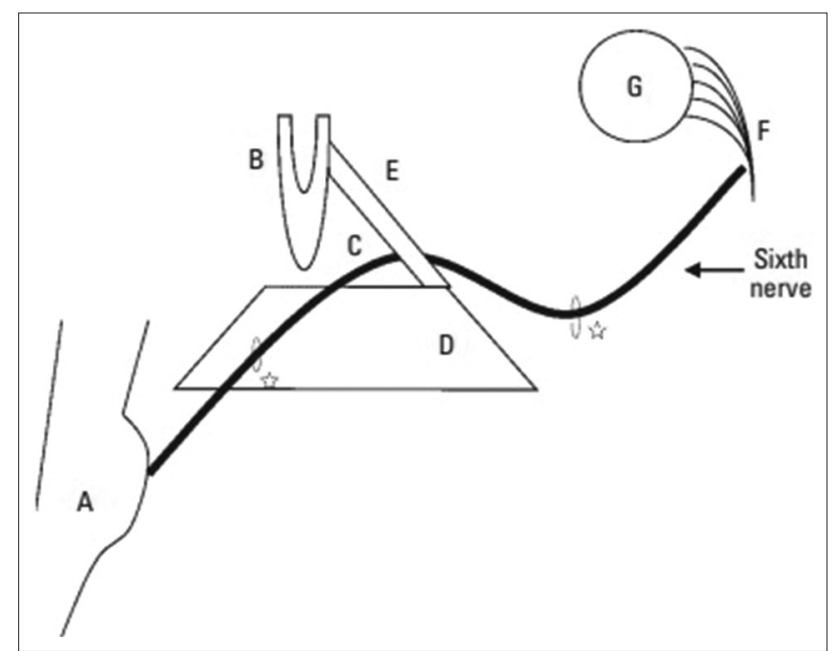

Figure 3: Schematic diagram of the course of the sixth cranial nerve from the pons $(A)$ to the lateral rectus muscle $(F)$. The nerve ascends over the petrous bone (D) and under Gruber's ligament (E) as it passes through Dorello's canal (C). The nerve is tethered by dura before and after the canal (stars). Injury to the peripheral nerve is thought to occur by contusion against the petrous ridge after midfrontal head impact. B, Posterior clinoidal process; G, globe

directed in the mid-frontal bone resulted in stretching of both the abducens nerves with the apex of the petrous bone acting as a fulcrum for compression of the nerves. ${ }^{10}$ 
Indeed, in the absence of skull fractures, the mechanism proposed by Takagi et al., would appear most appropriate. ${ }^{4}$ Following head injury with associated fracture of the skull base involving the clivus, clival epidural haematoma may occur. Epidural haematoma compresses the bilateral abducens nerve resulting in injury. ${ }^{11}$ In 1985, Arias et al concluded that the points of entry of the nerve into both the extradural space and the petrous ridge are the most probable locations for the avulsion of abducens nerve. ${ }^{1}$ Moreover, post-mortem analysis of ten post-traumatic bilateral abducens palsy cases at autopsy found injury to the nerve to be most evident at the sites of the dural entry point and petrous apex. ${ }^{12}$ Keane et al., in 1976 suggested that the incidence of traumatic bilateral abducens palsy is similar to that of unilateral palsy. It has been postulated that the apparent paucity of reported bilateral cases is due to patients not surviving the initial trauma due to severity of injury. ${ }^{13} \mathrm{~A}$ review by Arias et al., in 1985 identified 10 cases of traumatic bilateral abducens palsy, of which 3 had an associated cervical spine fracture without skull fracture. ${ }^{1}$ Lazow et al., reported an additional three cases in $1995 .{ }^{4}$

Delayed presentation of post-traumatic bilateral abducens palsy is very rare with only six cases reported in the literature. The mechanism for a delayed presentation of bilateral abducens palsy is unclear. Many mechanisms have been proposed which includes vascular causes like vasospasm and ischemia. It is related to disruption of blood supply from branches of the meningodorsal artery and also tissue edema, similar to the mechanism of delayed onset traumatic $7^{\text {th }}$ nerve palsy. ${ }^{14,15}$

Increase in size of post traumatic retroclival epidural haematoma, causes posterior displacement of brainstem leading to abnormal stretching of the bilateral abducens nerve anywhere along its course. Progressive edema may impinge on the sheath of the nerve, leading to axonal damage of the nerve. ${ }^{16}$ Additionally, delayed intracranial haemorrhage has been postulated to be other mechanism, with asymptomatic time of up to 1 month reported in cases of delayed intra cranial haemorrhage. ${ }^{17}$ Devin K. Binder et al., had reported a case with depressed skull fracture compressing superior sagittal sinus causing raised Intracranial pressure and bilateral abducens palsy on $4^{\text {th }}$ day. Post operatively after removing the depressed fragments, the nerve palsy improved. ${ }^{18}$ Nayil K et al., reported had reported a case with head injury with CT brain suggestive of vertex Extradural haemorrhage with delayed signs of raised intracranial pressure symptoms along with bilateral abducent nerve palsy. Post operatively abducens nerve palsy improved. ${ }^{19}$ Elevated intracranial pressure is known to cause bilateral abducens palsy. This may be one of the mechanisms of delayed-onset bilateral abducens paresis following head injury. Thus, there may be other reasons of delayed-onset bilateral abducens nerve palsy apart from direct trauma to the nerve. ${ }^{14}$ Ravindran et al postulated that partial avulsion of the abducens nerve, sustained at the time of initial trauma, followed by stretching or compression of the nerve by a combination of the mechanisms could result in delayed complete avulsion of the nerve. ${ }^{20}$

Out of 51 publications which include 139 cases, forty- one cases presented with immediate bilateral palsy, six cases were of delayed presentation while in the rest of the cases the time of presentation was not mentioned. In our case, patient presented with immediate onset of bilateral abducens palsy. On imaging clival fracture was seen in CT brain, which can be attributed for the nerve injury. The most common associated nerves involved along with bilateral abducens nerve injury are facial and hypoglossal nerves. ${ }^{21-29}$

Other nerves involved according to literature review were oculomotor, trochlear, trigeminal nerves. ${ }^{18,30,31}$ Cases with retroclival extradural haematoma had higher chances of multiple cranial nerve injuries. ${ }^{22-24,26}$ Cases with multiple basal skull fracture involving petrous temporal bone fracture had higher chances of facial nerve injury. ${ }^{21,30,31}$ Our case presented with associated right facial nerve involvement which can be attributed to linear un-displaced fracture in mastoid part of right temporal bone.

We cannot comment on the rate of recovery in our review as different publications have chosen different time period for recovery. Few publications mention partial recovery at their follow-up. In our review, twenty-three patients show recovery while 29 patients did not recover irrespective of the follow up period mentioned by the authors. In rest of the cases, the recovery was not mentioned. Holmes et al., ${ }^{32}$ reported spontaneous recovery in $38 \%$ of bilateral traumatic abducens palsy at 3 months of follow-up. Mutyala et al. ${ }^{33}$ reported a recovery rate of $12 \%$ in the same. However, they did not mention the time period of follow -up. Unilateral $6^{\text {th }}$ nerve palsy has been reported to recover spontaneously in $12-73 \% .^{32,33}$

Our case showed no improvement in bilateral abduction during follow-up at 6 months, however facial nerve palsy improved to grade 2. Along with bilateral involvement, the poorer outcome can be related with the severity of the adduction deficit, with complete deficits having lower rates of spontaneous recovery..$^{34}$ Majority of the publications on recovery are limited by the small number of sample size. Cases of bilateral abducens nerve palsy following trauma are probably rare as the force required is usually not compatible with life. For the same reason, traumatic bilateral abducens nerve palsies are frequently accompanied with life-threatening injuries like skull base fracture. ${ }^{8}$ 


\section{CONCLUSION}

To summarize, clinical presentation of traumatic bilateral abducens nerve palsy is rare following closed head trauma and is usually associated with other injuries which are incompatible with life. Due to its long intracranial course, abducens nerve is vulnerable for injury and various mechanisms have been described separately for immediate and delayed presentation. It can be associated with other nerve injuries depending on basal skull fractures. Severity of abduction deficits and bilateral nerve injury are independent risk factors for poor outcome.

\section{REFERENCES}

1. Arias MJ. Bilateral traumatic abducens nerve palsy without skull fracture and with cervical spine fracture: case report and review of the literature. Neurosurgery. 1985;16(2):232-234.

https://doi.org/10.1227/00006123-198502000-00020

2. Marconi F, Parenti G and Dobran M. Bilateral traumatic abducens nerve palsy. Case report. J Neurosurg Sci. 1994;38(3):177-180.

3. Ono K, Arai H, Endo T, Tsunoda A, Sato K, Sakai T, et al. Detailed MR imaging anatomy of the abducent nerve: evagination of CSF into Dorello canal. AJNR Am J Neuroradiol. 2004;25(4):623-626.

4. Lazow SK, Izzo SR, Feinberg ME and Berger JR. Bilateral abducens nerve palsy secondary to maxillofacial trauma: report of case with proposed mechanism of injury. J Oral Maxillofac Surg. 1995;53(10):1197-1199.

https://doi.org/10.1016/0278-2391(95)90634-7

5. Limnaios EE and Papageorgiou CT. Bilateral abducens nerve palsy. Ophthalmologica. 1980; 181:326-329.

https://doi.org/10.1159/000309071

6. Baker RS and Epstein AD. Ocular motor abnormalities from head trauma. Surv Ophthalmol. 1991; 35:245-267.

https://doi.org/10.1016/0039-6257(91)90046-I

7. Nathan $\mathrm{H}$, Ouaknine $\mathrm{G}$ and Kosary IZ. The abducens nerve: Anatomical variations in its course. Journal of neurosurgery. 1974;41(5):561-566.

https://doi.org/10.3171/jns.1974.41.5.0561

8. Advani RM and Baumann MR. Bilateral sixth nerve palsy after head trauma. Annals of emergency medicine. 2003;41(1):27-31. https://doi.org/10.1067/mem.2003.46

9. Schneider RC and Johnson FD. Bilateral traumatic abducens palsy: a mechanism of injury suggested by the study of associated cervical spine fractures. Journal of neurosurgery. 1971;34(1):33-37.

https://doi.org/10.3171/jns.1971.34.1.0033

10. Takagi H, Miyasaka Y, Kuramae T, Ohwada T and Tsunoda M. Bilateral traumatic abducens nerve palsy without skull fracture or intracranial hematoma-a report of 3 cases and consideration of the mechanism of injury (author's transl). No shinkei geka. Neurological surgery. 1976;4(10):963-969.

11. Garton HJ, Gebarski SS, Ahmad O and Trobe JD. Clival epidural hematoma in traumatic sixth cranial nerve palsies combined with cervical injuries. Journal of Neuro-Ophthalmology. 2010;30(1):18-25.

https://doi.org/10.1097/WNO.0b013e3181ce14ae

12. Sam B, Ozveren MF, Akdemir I, Topsakal C, Cobanoglu B, Baydar CL, et al. The mechanism of injury of the abducens nerve in severe head trauma: a postmortem study. Forensic science international. 2004;140(1):25-32.

https://doi.org/10.1016/j.forsciint.2003.11.020

13. Keane JR. Bilateral sixth nerve palsy: analysis of 125 cases. Archives of neurology. 1976;33(10):681-683. https://doi.org/10.1001/archneur.1976.00500100015007

14. Salunke P, Savardekar A and Sura S. Delayed-onset bilateral abducens paresis after head trauma. Indian journal of ophthalmology. 2012;60(2):149.

https://doi.org/10.4103/0301-4738.90491

15. Kim MS, Cho MS and Kim SH. Delayed bilateral abducens nerve palsy after head trauma. Journal of Korean Neurosurgical Society. 2008;44(6):396.

https://doi.org/10.3340/jkns.2008.44.6.396

16. Lee SJ, Yang HK, Ji MJ, Kim M, Hwang JM and Han SB. Delayed unilateral abducens nerve palsy following contralateral posttraumatic epidural hematoma. British journal of neurosurgery. 2016;30(1):120-121.

https://doi.org/10.3109/02688697.2015.1073221

17. Itshayek E, Rosenthal G, Fraifeld S, Perez-Sanchez X, Cohen JE and Spektor S. Delayed posttraumatic acute subdural hematoma in elderly patients on anticoagulation. Neurosurgery. 2006;58(5): A851-A856.

https://doi.org/10.1227/01.NEU.0000209653.82936.96

18. Binder DK, Sarkissian V, Schmidt MH and Pitts LH. Resolution of intracranial hypertension after elevation of depressed cranial fracture over the superior sagittal sinus: case report. Neurosurgery. 2004;55(4): E1018-E1022. https://doi.org/10.1227/01.NEU.0000137329.13981.01

19. Nayil K, Laharwal M, Dhar A, Wani A, Ramzan A and Arif S. Vertex epidural hematoma with bilateral abducent nerve palsy: case report and literature review. Turk Neurosurg. 2012; 22:257-260.

20. Ravindran K, Lorensini B, Gaillard F and Kalus S. Bilateral traumatic abducens nerve avulsion: A case series and literature review. J Clin Neurosci. 2017; 44:30-33.

https://doi.org/10.1016/j.jocn.2017.06.023

21. Lee GYF and Halcrow S. Petrous to Petrous Fracture Associated with Bilateral Abducens and Facial Nerve Palsies: A Case Report. The Journal of Trauma: Injury, Infection, and Critical Care. 2002; 53:583-585. https://doi.org/10.1097/00005373-200209000-00034

22. Calisaneller T, Ozdemir $\mathrm{O}$ and Altinors N. Posttraumatic acute bilateral abducens nerve palsy in a child. Childs Nerv Syst. 2006; 22:726-728. https://doi.org/10.1007/s00381-005-0036-9

23. Ratilal B, Castanho P, Vara Luiz C and Antunes JO. Traumatic clivus epidural hematoma: case report and review of the literature. Surg Neurol. 2006; 66:200-202.

https://doi.org/10.1016/j.surneu.2005.11.030

24. Kwon TH, Joy H, Park YK and Chung HS. Traumatic retroclival epidural hematoma in a child: case report. Neurol Med Chir (Tokyo). 2008; 48:347-350.

https://doi.org/10.2176/nmc.48.347

25. Pancko FX and Barrios TJ. Post-Traumatic Bilateral Abducens Nerve Palsy and Unilateral Facial Nerve Palsy: A Case Report. Journal of Oral and Maxillofacial Surgery. 2010; 68:1694-1697. https://doi.org/10.1016/j.joms.2009.05.443

26. Topcu-Yilmaz $P$ and Repka MX. Abducens nerve palsy associated with a clival epidural hematoma. J AAPOS. 2011; 15:69-70.

https://doi.org/10.1016/j.jaapos.2010.10.010 
27. Selçuk F and Mut SE. A case of traumatic bilateral abducens and unilateral hypoglossal nerve palsy. Am J Case Rep. 2013; $14: 230-234$

https://doi.org/10.12659/AJCR.889065

28. Salunke P, Madhivanan K, Kamali N and Garg R. Spontaneous recovery of post-traumatic acute bilateral facial and abducens nerve palsy. Asian J Neurosurg. 2016; 11:446.

https://doi.org/10.4103/1793-5482.145056

29. Paiva AL, de Aguiar GB, Ferraz VR, Araújo JL, Toita MH and Veiga JC. Retroclival Pneumocephalus Associated with Bilateral Abducens Palsy in a Child. Pediatr Neurosurg. 2016; 51:269-272. https://doi.org/10.1159/000445905

30. Lepore FE. Disorders of Ocular Motility Following Head Trauma. Archives of Neurology. 1995; 52:924-926.

https://doi.org/10.1001/archneur.1995.00540330106022

31. Ruiz-de-Río N, Arbizu-Duralde A, Miranda-Lloret $P$,
Asencio Durán M and Peralta-Calvo J. Bilateral sixth nerve and left third nerve palsy after head trauma. Arch Soc Esp Oftalmol. 2006; 81:41-44.

https://doi.org/10.4321/S0365-66912006000100010

32. Holmes JM, Droste PJ and Beck RW. The natural history of acute traumatic sixth nerve palsy or paresis. JAAPOS. 1998; 2:265-268.

https://doi.org/10.1016/S1091-8531(98)90081-7

33. Mutyala S, Holmes JM, Hodge DO and Younge BR. Spontaneous recovery rate in traumatic sixth-nerve palsy. Am J Ophthalmol. 1996; 122:898-899.

https://doi.org/10.1016/S0002-9394(14)70394-0

34. Holmes JM, Beck RW, Kip KE, Droste PJ and Leske DA. Predictors of nonrecovery in acute traumatic sixth nerve palsy and paresis. Ophthalmology. 2001; 108:1457-1460.

https://doi.org/10.1016/S0161-6420(01)00633-9

\section{Author's Contribution:}

SBV-Concept and design of the study; prepared first draft of manuscript, Interpreted the results; reviewed the literature and manuscript preparation, Concept coordination; RKR-Concept and design of the study; prepared first draft of manuscript reviewed the Literature and manuscript preparation; Concept coordination, revision of the manuscript; MSB-Concept and design of the study, prepared first draft of manuscript Concept coordination, review of literature and Interpreted the results, manuscript preparation,revision of the manuscript; AK-Manuscript preparation and Editing; IVN-Manuscript preparation and Editing; SPP-Manuscript preparation and editing.

Work attributed to:

Vydehi Institute of Medical Sciences and Research Hospital, Bangalore, Karnataka India.

Orcid ID:

Dr. Sandeep BV- (D http://orcid.org/0000-0003-4248-9062

Dr. Rekha KR- (1) https://orcid.org/0000-0003-4916-7074

Dr. Manpreet Singh Banga- (1) https://orcid.org/0000-0001-9102-9041

Dr. Anantha Kishan- (D) http://orcid.org/0000-0002-5778-1579

Dr. Vittal I Nayak- (i) https://orcid.org/0000-0002-6871-2667

Dr. Sneha Priya Prabhakar- (1) http://orcid.org/0000-0002-5361-5178

Source of Funding: None, Conflict of Interest: None. 